\title{
VIVER AO AR LIVRE: ENTRE PRESCRIÇÕES HIGIÊNICAS, ALEGRIA E AVENTURA
}

\section{LIVING OUTDOORS: BETWEEN HYGIENIC PRESCRIPTIONS, JOY AND ADVENTURE}




Uma menina brinca com seus companheiros no jardim, ao ar livre; um menino, que não se esquece de fazer "sua ginástica diária", lança-se à piscina e nada. Os dois personagens encenam as situações exemplarmente apresentadas na obra do professor Deodato de Moraes, intitulada Vida Hygienica: historia, em figuras de duas crianças que nunca ficaram doentes, publicada pela Companhia Melhoramentos, em 1927 (Fig. 1). Os textos que acompanham as duas cenas versam sobre os benefícios dos exercícios físicos moderados e constantes para a saúde, entre os quais se incluem "uma circulação mais vigorosa do sangue" (MORAES, 1927, p. 16-17), o desenvolvimento dos músculos, o aumento do apetite, um sono tranquilo e reparador. A tudo isso soma-se a aprendizagem da prudência e da importância do esforço. Nesses textos, o contato com a natureza figura como aspecto fundamental, a tornar os exercícios físicos ainda mais proveitosos, conforme sentencia o autor:

Para melhor resultado, os exercicios devem ser feitos, de preferencia ao ar livre, em alegres diversões, brinquedos e jogos. Não temas o sol! Elle é o maior amigo da tua saude. [...] Praticado ao ar livre, em tanques ou ribeirões de agua limpa, [o ato de nadar] é o exercicio physico ideal (MORAES, 1927, p. 17).

A tematização da natureza e de seus elementos, nos textos e imagens de um livro escolar publicado em São Paulo, no início do século XX, o qual contou com oito edições (a última delas de 1947), atesta a permanência de uma nova compreensão, lentamente elaborada, cujas primeiras manifestações têm lugar muito antes da publicação dessa modalidade de textos destinados às crianças das escolas brasileiras. Conforme assinala Thomas (1988, p. 18), no que se refere ao mundo ocidental, “[...] foi entre os anos de 1500 e 1800 que teriam ocorrido transformações profundas na maneira pela qual homens e mulheres, de todos os níveis sociais, percebiam e classificavam o mundo natural ao seu redor". Esse período seria marcado, segundo o autor, pelo surgimento de uma nova sensibilidade em relação aos animais, às plantas e, mais amplamente, à paisagem, como também pela formação de um pensamento acerca da natureza e de seus elementos calcado na ciência moderna e interessado em descrever seus fenômenos com precisão e detalhe. Nesse sentido, o período se caracterizaria, também, segundo Thomas, pelo desejo de medir para conhecer, bem como pela afirmação e produção de uma forma inédita de relação com a natureza, que inclui o apreço pela visitação a lugares distantes, pela contemplação do espetáculo de uma paisagem.

A paisagem ${ }^{1}$ e o olhar que lançamos a ela também resulta de processos culturais amplos, de uma educação mais específica do olhar e da mobilização de outros sentidos, pois, conforme analisou Schama (1996, p. 14), em seu livro Paisagem e memória: “[...] a natureza selvagem não demarca a si mesma, não se nomeia”. Assim, “[...] antes de poder ser um repouso para os sentidos, a paisagem é obra da mente. Compõe-se tanto de camadas de lembranças quanto de estratos de rochas" (SCHAMA, 1996, p. 16-17). Ainda segundo o autor, nem "[...] todas as culturas abraçam a natureza e a paisagem com igual ardor, e as que as abraçam conhecem fases de maior ou menor entusiasmo" (SCHAMA, 1996, p. 25). A natureza como espaço de educação, divertimento, cura e prevenção de doenças exige, portanto, certo distanciamento, configurando-se em um lugar que se escolhe para ir, um lugar do qual aqueles que possuem tempo para estar ali extraem prazer, um lugar que pode, enfim, educar indivíduos e grupos.

Nessa direção, o século XVIII vê emergir uma narrativa bastante positiva da natureza, evocando generosidade e benevolência como valores a ela associados. Deve-se a Rousseau a formalização mais precisa de uma compreensão que a toma como uma espécie de guia e modelo para os processos educativos, contribuindo para torná-la lugar de práticas distintas e plurais, cujos rastros são percebidos nos séculos 
seguintes,comoevidenciamalgunsdosartigosreunidosnestedossiê.Éparticularmentena obraEmílio, publicada em 1762, que Rousseau postula, de modo mais preciso e detalhado, o lugar da natureza e de seus elementos na educação das crianças e jovens. É também nessa obra que enuncia, por meio da apreensão de sentimentos e de sensações, o papel da natureza física como capaz de educar integralmente o ser humano (RAMOS, 2016). A importância atribuída à natureza aponta para modificações mais amplas no âmbito de um pensamento educacional, largamente atravessado por influências médico-higienistas e naturistas.

Entre fins do século XIX e as três primeiras décadas do século XX, a natureza é objeto de um conjunto de intervenções que visam reconfigurá-la com o intento de constituí-la, efetivamente, como lugar de educação, divertimento e cura. O período é marcado por iniciativas que visam instaurar uma outra ordem urbana (ROCHA, 2003). Distintos projetos de remodelação das cidades articulam-se aos propósitos de criação de novos espaços, capazes de assegurar a conformação de um ideário de vida ao ar livre, tais como jardins públicos, parques e praças, ruas arborizadas, clubes esportivos e recreativos. Paralelamente a esse novo desenho do espaço urbano, emergem inúmeras atividades de recreio, como piqueniques, passeios a pé ou de bicicleta, banhos de rio e de mar, excursões ao campo, às praias e às montanhas, entre outras, pensadas como práticas que intentavam educar a população, ensinando-lhe novos modos de vida e novas formas de contato com o ar puro das montanhas, o sol, as margens dos rios e as praias.

A natureza instala-se, assim, no coração das reflexões educativas, compondo procedimentos e conformando experiências singulares. Na Europa, ideias naturistas nutrem de maneira notória a corrente da Escola Nova e, na França, encontram expressão privilegiada nas escolas ao ar livre, instituições que também tiveram alguma repercussão no Brasil (VILLARET, 2005; DALBEN, 2014). A constituição e a divulgação de um conjunto de ideias articuladas em torno de um ideal de vida ao ar livre no Brasil urbano são perceptíveis, no período, em atos administrativos, assim como na imprensa. Nesses registros, podem-se identificar, também, ideias e práticas nudo-naturistas, pelo menos desde a década de 1930. Assim, na divulgação do naturismo, a relação entre educação, higiene e saúde pode ser apreendida, expressando-se em variadas representações de natureza.

No caso brasileiro, esse período é emblemático da adesão a essas ideias, atravessadas, especialmente a partir dos anos 1930, por uma compreensão de que evocar a natureza e seus elementos é, também, evocar as férias, o tempo de repouso e de recomposição das forças e da energia, ou, ainda, é aludir aos esportes, aos divertimentos ao ar livre e aos cuidados terapêuticos. Em outras palavras, é insistir nos benefícios do sol e do ar puro, em contraposição aos riscos do confinamento e do amontoamento (MEDEIROS, 2016; MEDEIROS; SOARES, 2016, 2017). Uma racionalização das referências se acentua, observando-se, assim, a afirmação de uma ideia de natureza ajardinada, apaziguada, aprazível, aquela que foi produzida pela mão humana e que passa a emoldurar as cidades brasileiras, tornando-se mais um testemunho da tão desejada modernização. Tal ideário convive com representações de uma natureza selvagem e indômita - povoada por ameaçadores seres, causadores dos mais diferentes males, cujo contato representava uma séria ameaça à saúde -, bem como de uma população inculta, vivendo em meio à sujeira e à ignorância, afeita a hábitos que ameaçavam o projeto de modernidade que se buscava erigir, tão presente nas narrativas médicas acerca do universo rural brasileiro ${ }^{2}$.

As reflexões em torno das quais se articula o presente dossiê procuram flagrar os modos como um ideário de vida ao ar livre, marcado por essas ambiguidades, forjou-se e ganhou ampla divulgação, expressando-se em distintos registros e contribuindo para a afirmação da natureza e de seus elementos como centrais na educação, na prevenção das doenças, na preservação da saúde e nos divertimentos de populações que viviam em aglomerações urbanas nas primeiras décadas do século XX. 
É nesse período que são desenhados com mais precisão ideias e ideais que, por vezes, surgem como prescrições médicas e/ou pedagógicas e podem ser apreendidas em diferentes registros, como se pode observar nos artigos aqui reunidos. Valores correlatos ao urbano começam a se impor e circular por diferentes meios. Um dos modos de apreensão é a imprensa que contribui para a universalização de representações acerca de diferentes temas, entre eles o da importância da vida ao ar livre. Jornais e revistas surgem e, por vezes, desaparecem em uma velocidade surpreendente, mas deixam o registro daquilo que um determinado grupo compreendia como sendo importante, sejam as revistas de perfil científico, sejam aquelas de variedades. Estas últimas, de caráter mais ligeiro e de fácil consumo, desenhavam diferentes prescrições e conselhos acerca de hábitos e comportamentos, entre os quais a prática de exercícios físicos e esportes ao ar livre, assim como passeios em estações termais, colônias de férias, balneários litorâneos, piqueniques e múltiplas formas de convívio junto à natureza ${ }^{3}$.

Lançando mão de outra linguagem, elas testemunham uma ascensão de preceitos e práticas encontrados, por exemplo, em boletins e anais de congressos médicos e educacionais, os quais afirmam insistentemente os benefícios dos exercícios corporais e dos esportes ao ar livre. Essas práticas expressam a lenta modernização da sociedade, acentuada nos anos 1920, período em que se observa uma adesão mais ampla a elas. Concebidas como práticas educativas, curativas e de diversão, elas deveriam ser realizadas ao ar livre, em clubes, parques e jardins, como também nos pátios das escolas. Trata-se aqui do surgimento de outro regime de emoções, aquele mesmo que ensina a extrair prazer junto a uma natureza transformada pela mão humana ou, ainda, a sonhar com a felicidade que pode resultar de uma vida saudável.

Os anais e as atas dos congressos médicos e educacionais também registraram uma atenção à vida ao ar livre e a uma educação pela e na natureza, sublinhando práticas e procedimentos que deveriam atingir as populações urbanas, inclusive em seus divertimentos, sem descurar dos riscos potenciais da vida nas regiões rurais, marcadas pelo signo do atraso e da doença ${ }^{4}$. Em suas páginas, encontram-se recomendações e prescrições que buscavam alcançar as cidades brasileiras, cujos ecos também se faziam presentes nos manuais escolares, os quais contemplavam indicações médicas e pedagógicas acerca dos benefícios do ar puro, do sol, dos jardins e parques, ou, ainda, da necessidade de usufruir as férias no campo, na praia, na montanha (SOARES, 2016; ROCHA, 2003, 2017).

"Viver o mais longamente possível ao ar livre, ou em lugares onde o ar não fique parado e quente" (I CONGRESSO BRASILEIRO DE HYGIENE, 1923, p. 26), era o que recomendava a Associação Cristã dos Moços na tese apresentada no I Congresso Brasileiro de Hygiene, realizado em 1923, na cidade do Rio de Janeiro. Em uma direção próxima a essa, o médico Wilh. Erwin Engelhardt, ao escrever sobre a fadiga do trabalhador, tema recorrente nas preocupações das autoridades públicas, nos anos 1930, afirmava ser necessário realizar atividades compensatórias ao trabalho para combater a fadiga. Para tanto, indicava as ginásticas em meio ao ar puro e fresco, nos intervalos do trabalho e, quando possível, em tempos mais prolongados, após o trabalho, “[...] a actividade sportiva, [e] passeios no campo" (BOLETIM DE HYGIENE MENTAL, 1930).

O médico Colombo Spindola, quatro anos antes, já ressaltava que viver sadiamente exigia um “[...] repouso suficiente e um trabalho metódico de exercícios moderados ao ar livre [...]" (III CONGRESSO BRASILEIRO DE HYGIENE, 1926, p. 861). De igual modo, o Dr. Waldomiro Pereira, em 1929, fazia alusão aos benefícios da vida ao ar livre, afirmando ser a educação física e o esporte, praticados em parques, verdadeiros saneadores do meio, razão pela qual propunha que esses espaços fossem:

[...] distribuídos pelos núcleos da população, [pois] garantem não só permanente e efetiva atuação, como podem trazer a melhor cooperação nas campanhas sanitárias, 
pelo atrativo que exercem principalmente sobre as crianças e a mocidade, que para freqüentá-los submeter-se-iam facilmente as exigências de assistência sanitária (V CONGRESSO BRASILEIRO DE HYGIENE, 1929, p. 140).

Assim como nos manuais escolares, de que é exemplo a narrativa de vida higiênica produzida por Deodato de Moraes, as revistas pedagógicas também trazem em suas páginas inúmeras referências aos benefícios de uma vida ao ar livre, pondo em circulação conselhos e prescrições evocadas por médicos e sanitaristas. A Revista de Ensino de São Paulo, em seu número 3, de agosto de 1902, já assinalava a importância da natação, ao lado de outros exercícios realizados ao ar livre, enfatizando os benefícios para a saúde das crianças e dos jovens. Em 1912, a mesma revista, em seu número 2 (p. 17), enaltecia o modelo inglês de educação, ao sublinhar o lugar de destaque que ocupavam, pelo seu grande "valor educativo", os "jogos em pleno ar", os quais deveriam figurar nas escolas, tendo a "gymnastica scientífica" por complemento.

Em seus números 3 e 4, publicados em 1917 e 1918 respectivamente, ao tratar o tema "Hygiene e Educação", a revista exortava os professores a não se desinteressarem da educação física, considerando sua importância para o desenvolvimento físico. Recomendava, nesse sentido, a importância de:

[...] impulsionar este ramo da educação, estimulando a actividade da vida com jogos ao ar livre, marchas ao sol, a carreira, a gymnastica respiratória e outros exercicios naturaes, agindo não só sobre o physico como sobre a natureza moral da creança e reconstituindo-lhe o organismo em condições atmosphéricas mais favoraveis (REVISTA DE ENSINO..., p. 6-7).

Lamentava a falta de "excursões escolares obrigatórias, passeios, durante os quaes os professores aproveitam todas as oportunidades para desenvolver nas crianças as faculdades de observação" (p. 6-7).

A vida ao ar livre evocada no período atesta uma compreensão de que a natureza organizada para a recreação educa, regenera, revigora, previne, cura e diverte. Contudo, é sempre oportuno sublinhar que uma relação prazerosa e aventureira com a natureza e seus elementos também escapa aos enquadramentos evocados pela bandeira do higienismo e de um pensamento educacional afinado com os seus preceitos. Viver ao ar livre, assim, poderia representar aventura e contentamento, jogos corporais com os elementos da natureza, riso e júbilo ao sentir, simplesmente, que o sol brinca sobre a pele, que o ar roça e faz arrepiar o corpo, que as águas em suas diferentes temperaturas permitem emoções diversas, ou, simplesmente, que, contemplar uma paisagem acalma, pacifica, torna a vida menos rude, como sugere a imagem de capa da Fon Fon de 1929, ao fim desta apresentação (Fig. 2).

O conjunto de artigos reunidos neste dossiê pretende, assim, contribuir para fazer avançar a nossa compreensão sobre as representações da natureza em distintos momentos históricos e em diferentes contextos. As análises propostas oferecem pistas valiosas para a reflexão sobre os sentidos recobertos pelas complexas relações do ser humano com a natureza e seus elementos, expressas em formulações que vão desde o apelo à alegria e ao bem-estar, aos riscos e perigos do mundo natural, sem deixar de sinalizar para as recentes preocupações com as questões ambientais. Lançando mão de uma ampla e variada gama de fontes, que inclui revistas especializadas e de variedades, periódicos destinados ao público infantil, jornais, textos médicos, anais de congressos, guias turísticos, documentários, fontes oficiais (como relatórios, ofícios, programas de ensino), além de depoimentos, os autores convidam a uma profunda reflexão, que se volta para as dinâmicas sociais por meio das quais a natureza vai assumindo múltiplos e, em alguns casos, ambíguos significados. 
A crença na ação vitalizante e curativa dos elementos naturais, que se difunde internacionalmente no século XIX, encontra expressão, dentre outras formas, nas iniciativas de turismo terapêutico examinadas por Silvain Villaret, as quais põem em cena representações da natureza como cenário natural propício ao turismo e aos lazeres. O ideal de "retorno à natureza" identifica-se, nesse caso, a uma "aventura interior", traduzindo-se em práticas implicadas com a constituição da identidade do sujeito. A dimensão curativa mobilizada nas representações da natureza figura, numa outra dimensão, nas propostas voltadas para o enfrentamento de quadros mórbidos, como a tuberculose, conforme assinalam André Dalben e Henrique Mendonça da Silva, ao examinar as propostas de criação de instituições como solários, preventórios, colônias de férias infantis, aulas e escolas ao ar livre, no Rio de Janeiro do início do século XX. Os ideais do naturismo ecoam, ainda, nas reflexões em torno da nudez, em seus vínculos com a sexualidade, postas em circulação nas propostas de educação da infância revisitadas por Carlos Herold Junior. Propostas essas nas quais as preocupações com a natureza circundante se articulam às representações sobre a "natureza infantil".

A inscrição do corpo e de sua imagem, nos domínios da natureza, é o mote das reflexões de Alexandre Vaz, que analisa dois documentários produzidos nos anos 1930, encomendados e financiados pelo III Reich. Peças de propaganda do nacional-socialismo, os filmes são interrogados como dispositivos pedagógicos, no âmbito de um projeto que busca circunscrever o corpo ao plano de uma natureza pura e sem máculas, destituindo-o de historicidade e negando-lhe o caráter político. A relação com a natureza, tematizada em outra perspectiva, marca o discurso e as práticas pedagógicas relacionadas à alimentação implementadas na escola argentina, examinadas por Angela Aisenstein e Cecilia Almada. A natureza, nesse caso, articula-se de forma ambígua à produção dos alimentos bem como às práticas de alimentação, em suas relações com o funcionamento corporal e com atitudes morais ligadas à moderação, aspectos que deveriam ser ensinados em distintas disciplinas do currículo escolar.

O currículo escolar, em suas aproximações com o discurso veiculado pela imprensa, é também perspectivado, por meio do exame do ensino das variações do clima das diversas regiões do Brasil, proposto por Denise Sant'Anna, numa chave de leitura que busca capturar as emoções humanas relacionadas ao meio ambiente e, de modo particular, às maneiras de perceber e sentir os fenômenos climáticos. Os ecos do discurso dos sujeitos que vivenciam mudanças significativas nas relações com o mundo natural, impostas pelos processos de urbanização, fazem-se ouvir na reflexão sobre a ampliação dos limites da cidade de São Paulo, proposta por Janes Jorge. Suas análises permitem adentrar os meandros da transição entre o mundo rural e o urbano, fazendo emergir as perplexidades dos sujeitos diante da urbanização.

Corpos, nudez, luz solar, ar livre, banhos de mar, clima, lazeres, alimentação, repouso, doenças, pureza são alguns dos elementos presentes nas fontes selecionadas, cujos nexos com aspectos ligados à religião, à ciência, à moral, à política, ao nacionalismo não passam despercebidos nas análises que se entretecem no conjunto de textos aqui apresentados, construídos a par das argutas indagações que levantam sobre as representações e práticas em torno de uma natureza que educa, cura e regenera, mas também oferece perigos. Com a reunião destes textos, pretende-se lançar um convite para a reflexão sobre a natureza e os sentidos a ela atribuídos historicamente, num momento em que essa temática se coloca na ordem do dia, percorrendo desde os debates em torno do desmatamento e do aquecimento global, os temores acerca das visíveis mudanças no clima do planeta e do esgotamento dos recursos naturais, até as opções cotidianas sobre o que comer, o que beber, o que vestir, como se prevenir e tratar as doenças, em meio a uma oferta crescente de produtos e estilos de vida que apelam a uma certa relação com a natureza e seus elementos. 


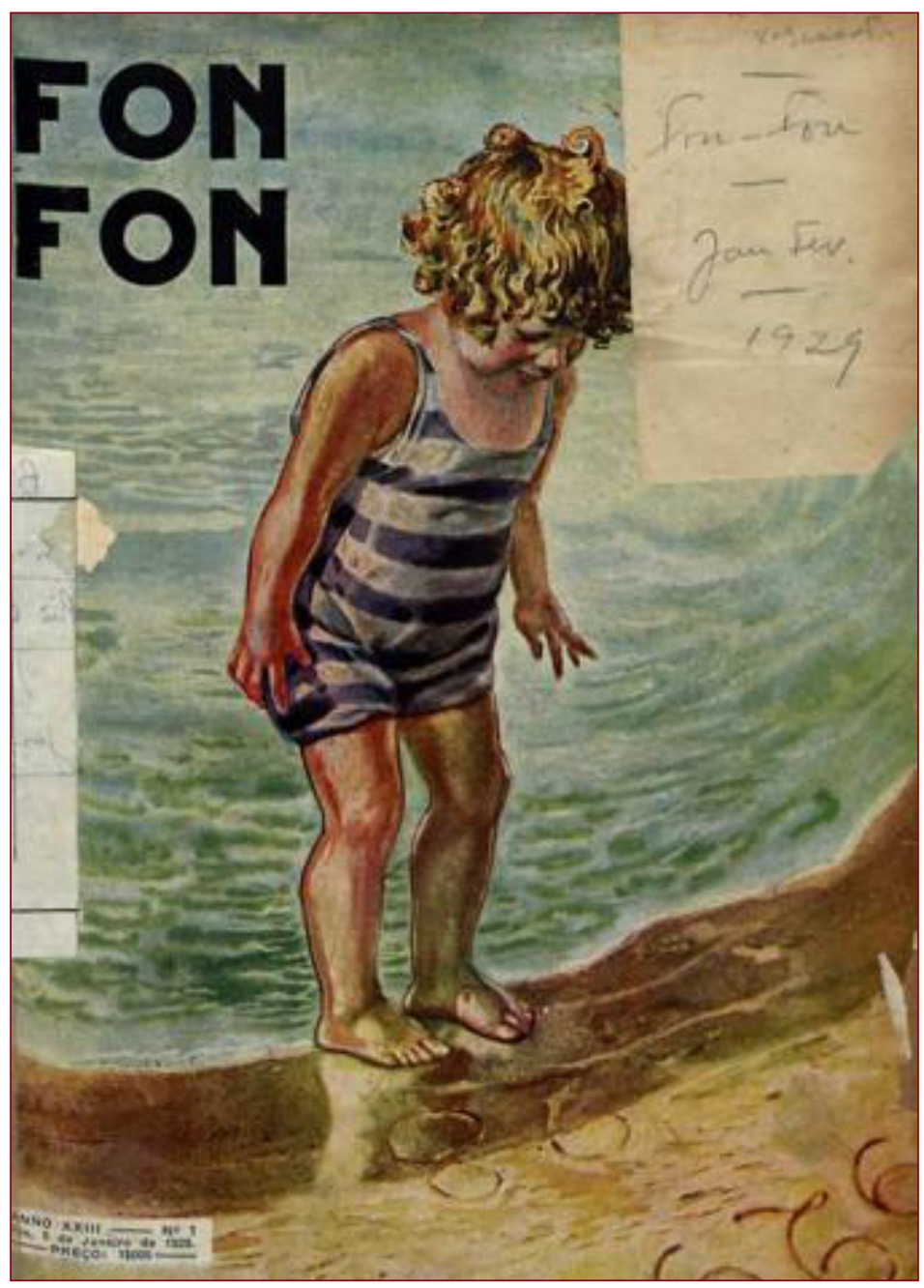

Fonte: (Fon Fon, 1929)

Figura 2. Capa da Fon Fon.

\section{Contribuições das Autoras}

Conceptualização: Soares CL, Rocha HHP; Metodologia: Soares CL, Rocha HHP; Redação Primeira versão: Soares CL, Rocha HHP; Redação - Revisão \& Edição: Soares CL, Rocha HHP.

\section{Notas}

1. Estudos sobre a paisagem foram também empreendidos por Corbin, autor que vem se dedicando aos estudos dos elementos da natureza para uma história das sensibilidades ao clima e à meteorologia. A esse respeito ver, entre outros, Corbin (2001) e Corbin (2013).

2. Ver a respeito em Neiva e Penna (1916); Penna (1923). Ver também as análises de Dalben (2009).

3. A imprensa (jornais e revistas de variedades) traduz, em linguagem acessível, concepções que se expressam em conselhos e prescrições de autoridades públicas. Para os propósitos deste dossiê, tomamos como exemplo a Fon Fon, n. 05/01/1929, cuja capa finaliza esta apresentação.

4. Essas concepções circularam nos anais de congressos médicos e educacionais realizados no período, bem como em publicações organizadas por associações e ligas, de que são exemplo as seguintes referências: I Congresso Brasileiro de Hygiene (1923), III Congresso Brasileiro de Hygiene (1926), V Congresso Brasileiro de Hygiene (1929), Departamento de Educação Física (1942), Boletim de Hygiene Mental (1929), Boletim de Hygiene Mental (1930), I Conferência Nacional de Educação (1927), III Conferência Nacional de Educação (1929), VII Congresso Nacional de Educação (1935). 


\section{REFERÊNCIAS}

BOLETIM DE HYGIENE MENTAL, 10., 1929, São Paulo: Liga Paulista de Hygiene Mental, 1929.

BOLETIM DE HYGIENE MENTAL, 17., 1930, São Paulo: Liga Paulista de Hygiene Mental, 1930.

I CONFERÊNCIA NACIONAL DE EDUCAÇÃO, 1., 1927, Anais... Curitiba, 1927.

III CONFERÊNCIA NACIONAL DE EDUCAÇÃO, 3., 1929, Anais... São Paulo, 1929.

I CONGRESSO BRASILEIRO DE HYGIENE, 1., 1923, Anais... Rio de Janeiro: Officinas Graphicas de Demographia Sanitária, 1923.

III CONGRESSO BRASILEIRO DE HYGIENE, 3., 1926, Anais... São Paulo: São Paulo, 1926.

IV CONGRESSO BRASILEIRO DE HYGIENE, 5., 1929, Anais... Recife: Officinas da Inspectoria de Demographia Sanitária, 1929.

VII CONGRESSO NACIONAL DE EDUCAÇÃO, 7., 1935, Anais... Rio de Janeiro, 1935.

CORBIN, A. L' Homme dans le paysage. Paris: Textuel, 2001.

CORBIN, A. (Org.). La pluie, le soleil et le vent: Une histoire de la sensibilité au temps qu'il fait. Paris: Aubier, 2013.

DALBEN, A. Educação do corpo e vida ao ar livre: natureza e educação física em São Paulo (1930-1945). 2009. 158 f. Dissertação (Mestrado em Educação Física) - Faculdade de Educação Física, Universidade Estadual de Campinas, 2009. Disponível em: http://repositorio.unicamp.br/bitstream/REPOSIP/274792/1/ Dalben_Andre_M.pdf. Acesso em: 29 jul. 2020.

DALBEN, A. Mais do que energia, uma aventura do corpo: as colônias de férias escolares na América do Sul (18821950). 2014. 389f. Tese (Doutorado em Educação) - Faculdade de Educação, Universidade Estadual de Campinas, Campinas, 2014. Disponível em: http://repositorio.unicamp.br/jspui/handle/REPOSIP/319162. Acesso em:28 jun. 2019.

DEPARTAMENTO DE EDUCAÇÃO FÍSICA. Relatório de 1942. São Paulo: Secretaria de Educação e Saúde Pública de São Paulo, 1942.

MEDEIROS, D. C. C. Viagens às estâncias hidrominerais de São Paulo: cura, regeneração, divertimento e educação do corpo nas décadas de 1930 e 1940. 2016. 142f. Dissertação (Mestrado em Educação) - Faculdade de Educação, Universidade Estadual de Campinas, Campinas, 2016. Disponível em: http://repositorio. unicamp.br/bitstream/REPOSIP/322653/1/Medeiros_DanieleCristinaCarqueijeiroDe_M.pdf. Acesso em: 5 jul. 2019.

MEDEIROS, D. C. C.; SOARES, C. L. Uma natureza que educa: as estâncias hidrominerais no Estado de São Paulo (1930-1940). Movimento, Porto Alegre, v. 23, n. 3, p. 949-962, 2017. https://doi.org/10.22456/1982-8918.71128

MEDEIROS, D. C. C.; SOARES, C. L. Entre a cura e o divertimento: as viagens de férias junto à natureza em estâncias hidrominerais (1930-1940). Revista Brasileira de Ciências do Esporte, Porto Alegre, v. 38, n. 3, p. 213-219, 2016. https://doi.org/10.1016/j.rbce.2014.04.002 
MORAES, P. D. Vida hygiênica!: história, em figuras, de duas crianças que nunca ficaram doentes. São Paulo: Melhoramentos, 1927.

NEIVA, A.; PENNA, B. Viagem cientifica pelo Norte da Bahia, sudoeste de Pernambuco, sul do Piauhí e de norte a sul de Goiaz. Memórias do Instituto Oswaldo Cruz, Rio de Janeiro, v. 8, n. 3, p.74-224. 1916. https:// doi.org/10.1590/S0074-02761916000300001

PENNA, B. Saneamento do Brasil. 2.ed. Rio de Janeiro: Typ. Revista dos Tribunais, 1923.

RAMOS, R. S. Educação, corpo e natureza na obra “O Emílio” de Jean-Jacques Rousseau. 2016. 101f. Dissertação (Mestrado em Educação) - Faculdade de Educação, Universidade Estadual de Campinas, Campinas, 2016. Disponível em:http://repositorio.unicamp.br/bitstream/REPOSIP/305312/1/Souza_RachelRamosde_M.pdf. Acesso em:28jun.2019.

REVISTA DE ENSINO de São Paulo, 1902-1918.

REVISTA FON-FON. Capa. Rio de Janeiro, ano XXIII, n. 1, 5 jan. 1929

ROCHA, H. H. P. A higienização dos costumes: educação escolar e saúde no projeto do Instituto de Hygiene de São Paulo (1918-1925). Campinas: Mercado de Letras/FAPESP, 2003.

ROCHA, H. H. P. Regras de bem viver para todos: a Bibliotheca Popular de Hygiene do Dr. Sebastião Barroso. Campinas: Mercado de Letras/FAPESP, 2017.

SCHAMA, S. Paisagem e memória. São Paulo: Companhia das Letras, 1996.

SOARES, C. L. (Org.). Uma educação pela natureza: a Vida ao ar Livre, o corpo e a ordem urbana. Campinas: Autores Associados, 2016.

SOARES, C. L. Verbete: Educação do Corpo. In: GONZÁLEZ, F. J.; FENSTERSEIFER, P. E. (Orgs.). Dicionário Crítico de Educação Física. Ijuí: UNIJUI, 2014, p. 219-225.

THOMAS, K. O homem e o mundo natural. São Paulo: Companhia da Letras, 1988.

VILLARET, S. Histoire du naturisme en France depuis le siècle des Lumières. Paris: Vuibert, 2005.

Carmen Lucia Soares ${ }^{1, *}$

Heloísa Helena Pimenta Rocha

Organizadoras

1.Universidade Estadual de Campinas - Faculdade de Educação Física - Campinas (SP), Brasil.

2.Universidade Estadual de Campinas - Faculdade de Educação - Campinas (SP), Brasil.

*Autora correspondente: soares.carmenlucia@gmail.com

Este dossiê é resultado de pesquisa financiada pelo Conselho Nacional de Desenvolvimento Científico e Tecnológico, 304254/2006-9: Vida ao ar livre, educação e natureza no Brasil (1920-1940); 303841/2017-6: A retórica da higiene: emoções, sentimentos e formação de hábitos.

Comitê Editorial dos Cadernos Cedes/Coordenação deste número: Alessandra Arce Hai e Ana Clara Bortoleto Nery 